OPEN ACCESS

Edited by:

Jiang-Jiang Qin,

Zhejiang Chinese Medical University,

China

Reviewed by:

Benjamin Le Calvé,

University of Namur, Belgium

Qiyang Shou,

Zhejiang Chinese Medical University,

China

Li Lin,

Huazhong University of Science and Technology, China

*Correspondence: Yukio Fujiwara

fuji-y@kumamoto-u.ac.jp

Yoshihiro Komohara

ycomo@kumamoto-u.ac.jp

Specialty section:

This article was submitted to Pharmacology of Anti-Cancer Drugs,

a section of the journal

Frontiers in Pharmacology

Received: 27 August 2019

Accepted: 24 February 2020

Published: 18 March 2020

Citation:

Pan C, Fujiwara Y, Horlad H,

Shiraishi D, Iriki T, Tsuboki J, Ikeda T and Komohara Y (2020) Flavonoid Compounds Contained in Epimedii Herba Inhibit Tumor Progression by

Suppressing STAT3 Activation

in the Tumor Microenvironment.

Front. Pharmacol. 11:262.

doi: 10.3389/fphar.2020.00262

\section{Flavonoid Compounds Contained in Epimedii Herba Inhibit Tumor Progression by Suppressing STAT3 Activation in the Tumor Microenvironment}

\author{
Cheng Pan ${ }^{1}$, Yukio Fujiwara ${ }^{1 *}$, Hasita Horlad ${ }^{1}$, Daisuke Shiraishi1,2, Toyohisa Iriki ${ }^{1,3}$, \\ Jyunko Tsuboki ${ }^{1,4}$, Tsuyoshi Ikeda ${ }^{5}$ and Yoshihiro Komohara ${ }^{1 *}$
}

${ }^{1}$ Department of Cell Pathology, Graduate School of Medical Sciences, Faculty of Life Sciences, Kumamoto University, Kumamoto, Japan, ${ }^{2}$ Department of Orthopedic Surgery, Graduate School of Medical Sciences, Faculty of Life Sciences, Kumamoto University, Kumamoto, Japan, ${ }^{3}$ Department of Respiratory Medicine, Graduate School of Medical Sciences, Faculty of Life Sciences, Kumamoto University, Kumamoto, Japan, ${ }^{4}$ Department of Obstetrics and Gynecology, Graduate School of Medical Sciences, Faculty of Life Sciences, Kumamoto University, Kumamoto, Japan, ${ }^{5}$ Faculty of Pharmaceutical Sciences, Sojo University, Kumamoto, Japan

M2-like tumor-associated macrophages (TAMs) in the tumor tissues promote tumor progression by various mechanisms and represent possible targets of antitumor therapy. In the present study, we tested whether compounds from Epimedii Herba inhibit macrophage polarization to the M2/protumorigenic phenotype and prevent tumor progression, using human monocyte-derived macrophages (HMDMs) and an animal sarcoma model. Four Epimedii Herba-derived flavonoid compounds, namely, limonianin, epimedokoreanin B, icaritin, and desmethylicaritin, inhibited CD163 expression and interleukin (IL)-10 production, which are known M2 markers, suggesting that these compounds inhibit M2 polarization. Among these compounds, epimedokoreanin B and limonianin suppressed STAT3 activation in HMDMs. Notably, epimedokoreanin B also suppressed cell proliferation by blocking STAT3 activation in Saos-2 human sarcoma and LM8 mouse sarcoma cell lines. Furthermore, oral administration of epimedokoreanin $B$ inhibited tumor growth in an LM8 tumor-bearing murine model. These results indicate that Epimedii Herba and Epimedii Herba-derived compounds, such as epimedokoreanin $\mathrm{B}$, may be potentially new agents that can be used for the treatment and prevention of various malignant tumors. They may also be promising compounds for targeting the tumor microenvironment by inhibiting M2 polarization of the TAMs.

Keywords: Epimedii Herba, STAT3, flavonoid, macrophage, tumor cells

\section{INTRODUCTION}

The heterogeneity of macrophage activation plays an important role in innate immunity and is involved in the pathogenesis of various diseases. Initially, in the 1990s, several differences were found between interferon (IFN)- $\gamma$-stimulated macrophages and interleukin (IL)-4-stimulated macrophages, and these were called classically and alternatively activated macrophages, respectively 
(Stein et al., 1992). Later, based on arginine metabolism, macrophages were characterized to be of two phenotypes, namely, Th1- and Th2-like phenotypes, also described as M1 and M2 phenotypes, respectively (Mills et al., 2000). Now these concepts have been blended, and the M1/M2 paradigm is well known. M1-like macrophages are proinflammatory, characterized by high levels of IL-1 $\beta$, tumor necrosis factor$\alpha$ (TNF- $\alpha)$, and IL-23 production, and are involved in the elimination of invading microorganisms. In contrast, M2-like macrophages are anti-inflammatory and are mainly involved in immunosuppression and tissue remodeling. M2-like macrophages produce high levels of IL-10 and low levels of IL12 and express special receptors such as the mannose receptor (CD206), class A scavenger receptor (SR-A, CD204), hemoglobin scavenger receptor (CD163), and DC-SIGN (CD209) (Mantovani et al., 2002, 2004, 2013; Martinez et al., 2006; Komohara et al., $2014,2015)$. The phenotype of macrophages is highly plastic and can change between the M1 and M2 phenotypes depending on the types of stimulii (Porcheray et al., 2005).

The presence of tumor-associated macrophages (TAMs) in tumor tissues is closely associated with the development of the tumor microenvironment (Lewis and Pollard, 2006; Komohara et al., 2014). Clinically, a higher number of infiltrating M2-like TAMs is generally associated with poor prognosis and higher grade of malignancy in patients with various cancers, including glioma, sarcoma, and lymphoma (Espinosa et al., 2009; Clear et al., 2010; Komohara et al., 2011b, 2014; Kurahara et al., 2011; Takeya and Komohara, 2016). In addition, in vitro studies have shown that M2-like TAMs can promote tumor cell proliferation, angiogenesis, invasion, and metastasis by secreting several kinds of protumor cytokines and chemokines (Mantovani et al., 2002; Pollard, 2004; Sica and Bronte, 2007). Therefore, inhibiting polarization of macrophages to the M2 phenotype is considered a promising approach for antitumor therapy.

In the present study, we tested whether compounds derived from Epimedii Herba inhibit the polarization of macrophages to the M2 phenotype using a screening system to identify compounds that inhibit tumor progression.

\section{MATERIALS AND METHODS}

\section{Cells and Cell Culture}

Saos-2 (a human sarcoma cell line) and LM8 (a mouse sarcoma cell line) cells were purchased from the RIKEN Cell Bank (Tsukuba, Japan) and cultured in RPMI 1640 supplemented with $10 \%$ fetal bovine serum (FBS), and $100 \mu \mathrm{g} / \mathrm{mL}$ penicillin and streptomycin. We had previously established a high metastaticpotential cell line, LM8 clone 5 (Horlad et al., 2013), and we used this clone for the in vitro and in vivo studies. These cells were regularly tested and found to be negative for mycoplasma contamination.

Peripheral blood mononuclear cells were obtained from healthy volunteers, and written informed consent was obtained from all the donors. All protocols using human materials were approved by the Kumamoto University Review Board (No. 486) and were conducted in accordance with the approved guidelines. Monocytes were isolated using Lymphoprep ${ }^{\mathrm{TM}}$ and then stimulated with GM-CSF ( $5 \mathrm{ng} / \mathrm{mL})$ or M-CSF $(100 \mathrm{ng} / \mathrm{mL})$ for 7 days to differentiate them into human monocytederived macrophages (HMDMs). HMDMs were cultured in DMEM supplemented with $2 \%$ FBS, and $100 \mu \mathrm{g} / \mathrm{mL}$ penicillin and streptomycin.

\section{General Procedure}

The NMR spectra were measured with a JEOL ECA 500 NMR spectrometer. Preparative HPLC was performed using a SIMADZU LC-20AT pump, JASCO 830-RI detector, Sugai U620 column heater, and column of COSMOSIL $5 \mathrm{C}_{18}$ AR-II (5 $\mu \mathrm{m}, \phi 10.0 \times 250 \mathrm{~mm}$, Nacalai Tasque Inc., Kyoto, Japan), SunFire Prep $\mathrm{C}_{18}$, X-Bridge Prep $\mathrm{C}_{18}(5 \mu \mathrm{m}, \phi 10.0 \times 250 \mathrm{~mm}$, Waters Co., MA, United States) with a flow rate of $2.0 \mathrm{~mL} / \mathrm{min}$ and column temperature of $40^{\circ} \mathrm{C}$. TLC was performed on precoated silica gel $60 \mathrm{~F}_{254}$ (Merck Ltd., Frankfurter, Germany) and detection was achieved by spraying with $10 \% \quad \mathrm{H}_{2} \mathrm{SO}_{4}$ followed by heating. Column chromatography was carried out on MCI gel CHP-20P (Mitsubishi Chemical Co., Tokyo, Japan), Sephadex LH-20 (GE Healthcare Bioscience Co., Uppsala, Sweden), $\mu$-Bonda Pak $\mathrm{C}_{18}$ (Waters Co., MA, United States), and silica gel 60 (230-400 mesh, Merck Ltd., Frankfurter, Germany).

\section{Plant Materials}

Epimedii Herba (lot number: C1S1504) was purchased from Uchida Wakan-yaku Co. Ltd. (Tokyo, Japan) according to the specifications in the Japanese Pharmacopeia, which permitted the use of Epimedium spp. including Epimedium pubescens Maximowicz, Epimedium brevicornu Maximowicz, Epimedium wushanense TS Ying, Epimedium sagittatum Maximowice, Epimedium koreanum Nakai, Epimedium grandiumum Morren var. thunbergianum Nakai, and Epimedium sempervirens Nakai. A voucher specimen was deposited at the herbarium of the Faculty of Pharmaceutical Sciences, Sojo University, Japan (SJU1103).

\section{Extraction and Isolation}

The aerial parts of Epimedium spp. $(3.0 \mathrm{~kg})$ were extracted twice with $\mathrm{MeOH}$ by sonication for $6 \mathrm{~h}(30 \mathrm{~min} \times 12)$ at room temperature $\left(20-25^{\circ} \mathrm{C}\right)$. The extract was concentrated under reduced pressure to obtain a residue $(485.0 \mathrm{~g})$. The residue was partitioned between $n$-Hexane and $80 \% \mathrm{MeOH}$, and the $80 \%$ $\mathrm{MeOH}$ layer was concentrated to give a residue $(408.1 \mathrm{~g})$, which was loaded onto a MCI gel CHP-20P column $[\phi 50 \times 300 \mathrm{~mm}$; eluted with $\mathrm{H}_{2} \mathrm{O}-\mathrm{MeOH}$ gradient $(0,50,100 \%$; each $\mathrm{MeOH} \%$; $1.5 \mathrm{~L}$ of each gradient solution)] to give three fractions. The second fraction ( $46.5 \mathrm{~g}$, eluted with $50 \% \mathrm{MeOH}$ ) was further applied to a MCI gel CHP20P column $[\phi 50 \times 300 \mathrm{~mm}$; eluted with $\mathrm{H}_{2} \mathrm{O}-\mathrm{MeOH}$ gradient $(50,60,70,80,100 \%$; each $\mathrm{MeOH} \%$; $1.5 \mathrm{~L}$ of each gradient solution)] to give five fractions (fractions 2-1-2-5). An aliquot of fraction 2-3 (5.3 g, eluted with 70\% $\mathrm{MeOH}$ from the MCI gel) was separated using a Sephadex LH-20 column $(\phi 20 \times 1000 \mathrm{~mm}$; eluted with $\mathrm{MeOH})$ and a $\mu$-Bonda Pak $\mathrm{C}_{18}\left[\phi 25 \times 200 \mathrm{~mm}\right.$; eluted with $\mathrm{H}_{2} \mathrm{O}-\mathrm{MeOH}$ gradient $[60 \%, 70 \%, 80 \%$; each $\mathrm{MeOH} \% ; 135 \mathrm{~mL}$ of each gradient 
solution)], successively, and then purified with preparative HPLC [COSMOSIL AR-II (70\% MeOH)] to give compounds $6(4.5 \mathrm{mg})$. The third fraction $(65.0 \mathrm{~g}$, eluted by $100 \% \mathrm{MeOH})$ was further applied to a MCI gel CHP20P column $[\phi 50 \times 300 \mathrm{~mm}$, eluted with $\mathrm{H}_{2} \mathrm{O}-\mathrm{MeOH}$ gradient $(0,50,60,70,80,90,100 \%$; each $\mathrm{MeOH} \%$; $1.5 \mathrm{~L}$ of each gradient solution)] to give seven fractions (fractions. 3-1-3-7). An aliquot of fraction 3-4 (9.0 g, eluted with $70 \% \mathrm{MeOH}$ from MCI gel) was loaded on a Sephadex LH-20 column $(\phi 20 \times 1000 \mathrm{~mm}$, eluted with $\mathrm{MeOH})$ and $\mu$-Bonda Pak $\mathrm{C}_{18}\left[\phi 25 \times 200 \mathrm{~mm}\right.$, eluted with $\mathrm{H}_{2} \mathrm{O}-\mathrm{MeOH}$ gradient $(60,70,80 \%$; each $\mathrm{MeOH} \% ; 135 \mathrm{~mL}$ of each gradient solution)], and $\mathrm{a} \mathrm{SiO}_{2}$ column $[\phi 10 \times 100 \mathrm{~mm}$, eluted with $\mathrm{CHCl}_{3}: \mathrm{MeOH}: \mathrm{H}_{2} \mathrm{O}=9$ : $\left.1: 0.1(v / v)\right]$, successively, and then purified with preparative HPLC [Sunfire Prep $\mathrm{C}_{18}(70 \% \mathrm{MeOH})$ ] to give compounds $\mathbf{1}(28.9 \mathrm{mg})$. An aliquot of fraction 3-5 (10.4 g, eluted by $80 \% \mathrm{MeOH}$ from MCI gel) was subjected to a Sephadex LH-20 column $(\phi 20 \times 1000 \mathrm{~mm}$, eluted with $\mathrm{MeOH}$ ), and then purified with preparative HPLC [COSMOSIL $5 \mathrm{C}_{18}$ AR-II $\left.(70 \% \mathrm{MeOH})\right]$ to give compounds 5 (3.3 $\left.\mathrm{mg}\right)$ and 2 (28.1 mg). An aliquot of fraction 3-6 (12.2 g, eluted by $90 \% \mathrm{MeOH}$ from MCI gel) was subjected to a Sephadex LH-20 column $(\phi 20 \times 1000 \mathrm{~mm}$, eluted with $\mathrm{MeOH})$ and a $\mu$-Bonda Pak $\mathrm{C}_{18}\left[\phi 25 \times 200 \mathrm{~mm}\right.$, eluted with $\mathrm{H}_{2} \mathrm{O}-\mathrm{MeOH}$ gradient (70, 80, 90\%; each $\mathrm{MeOH} \% ; 135 \mathrm{~mL}$ of each gradient solution)], successively, and then purified with preparative HPLC [COSMOSIL $5 \mathrm{C}_{18}$ AR-II $(85 \% \mathrm{MeOH})$ ] to give compounds 3 $(7.7 \mathrm{mg})$ and $4(33.7 \mathrm{mg})$. Icaritin and desmethylicaritin were obtained by an enzymatic hydrolysis of glucosides $\mathbf{5}$ and $\mathbf{6}$, respectively. To a solution of $5(2.0 \mathrm{mg})$ in acetate buffer $(1.0 \mathrm{~mL}$, $\mathrm{pH} 5.0,100 \mathrm{mM}), \beta$-glucosidase from almonds $(5.0 \mathrm{mg}, \mathrm{EC}$ 3.2.1.21, Sigma) was added and incubated for $12 \mathrm{~h}$ at $37^{\circ} \mathrm{C}$. The reaction was quenched by adding $\mathrm{MeOH}$, and the solvent was evaporated in vacuo to get a residue. The residue was purified with a $\mathrm{SiO}_{2}$ column $\left[\phi 8 \times 40 \mathrm{~mm}\right.$, eluted with $\mathrm{CHCl}_{3}$ : $\mathrm{MeOH}=20: 1(v / v)]$ to obtain the compound icaritin $(1.0 \mathrm{mg})$. In the same manor described above, compound 6 (2.0 mg) was treated with $\beta$-glucosidase to obtain desmethylicaritin $(1.0 \mathrm{mg})$. The chemical structure of compounds 1 (icariin), 2 (icariside II), 3 (limonianin), 4 (epimedokoreanin B), 5 (icariside I), 6 (epimedoside C), icaritin, and desmethylicaritin were identified by comparing with the authentication data $\left({ }^{1} \mathrm{H}\right.$ - and ${ }^{13} \mathrm{C}-\mathrm{NMR}$ data) published in literature (Mizuno et al., 1988; Li et al., 1994; Wen-Kui et al., 1998; Jung et al., 2005; Bacher et al., 2010; Quan et al., 2010).

\section{HPLC Analysis}

HPLC profiling was analyzed on a SIMADZU LC-10AD pump, SIMADZU SPD-10A detector, SIMADZU CTO-10AC column heater, and column of COSMOSIL 5C 18 AR-II $(5 \mu \mathrm{m}$, $\phi 4.6 \times 250 \mathrm{~mm}$, Nacalai Tasque Inc., Kyoto, Japan) with a flow rate of $1.0 \mathrm{~mL} / \mathrm{min}$, column temperature of $40^{\circ} \mathrm{C}$, and detection wavelength of $280 \mathrm{~nm}$. The stock solution of the compounds 1-6 were mixed with the same volume to make a standard solution. The solution was injected to the HPLC system $(10 \mu \mathrm{L})$. The third fraction (MCI gel CHP-20P eluted by $100 \% \mathrm{MeOH}$ ) was dissolved in DMSO at $10 \mathrm{mg} / \mathrm{mL}$ concentration and injected to the HPLC system $(10 \mu \mathrm{L})$.

\section{Preparation of Tumor Culture Supernatant (TCS)}

Cell lines were maintained in culture medium for $24 \mathrm{~h}$. The supernatant was used as the tumor culture supernatant (TCS) for the experiments.

\section{Measurement of the Effects of Extracts and Isolated Compounds on CD163 Expression}

All the test samples were initially dissolved in DMSO $(100 \mathrm{mg} / \mathrm{mL}$ for extracts and $10 \mathrm{mM}$ for pure compounds). The DMSO solutions were then diluted with cell culture medium to a concentration of $100 \mu \mathrm{g} / \mathrm{mL}$ for extracts and 5-30 $\mu \mathrm{M}$ for pure compounds. In all the procedures, including extraction, elution of fractions, and isolation of compounds (icariin, icariside II, limonianin, epimedokoreanin B, icaritin, and desmethylicaritin), the mixtures were dissolved well to avoid any precipitates. HMDMs $\left(1 \times 10^{4}\right.$ cells per well in a 96-well plate $)$ were incubated with the extracts and isolated compounds from Epimedii Herba for $24 \mathrm{~h}$ along with IL-10, followed by the determination of CD163 expression using cell enzyme-linked immunosorbent assay (cell-ELISA) as described previously (Komohara et al., 2006). Briefly, each well of a 96-well plate was blocked with Block Ace (DS Pharma Biomedical, Osaka, Japan) and washed thrice with washing buffer (PBS containing 0.05\% Tween 20). The wells were incubated with an anti-human CD163 antibody (AM-3K; $2 \mu \mathrm{g} / \mathrm{mL}$ ) for $1 \mathrm{~h}$. The wells were then incubated with a horseradish peroxidase (HRP)-conjugated anti-mouse IgG antibody after washing thrice with washing buffer, followed by addition of TMB Microwell Peroxidase Substrate (SeraCare Life Science Inc., Milford, MA, United States). The reaction was then terminated by the addition of $1 \mathrm{M}$ sulfuric acid, and the absorbance was read at $450 \mathrm{~nm}$ using a microELISA plate reader.

\section{Measurement of the Effects of the Isolated Compounds on IL-10, TNF- $\alpha$, and IL-1 $1 \beta$ Secretion}

Human monocyte-derived macrophages $\left(1 \times 10^{4}\right.$ cells per well in a 96-well plate) were stimulated with $100 \mathrm{ng} / \mathrm{mL}$ LPS for $24 \mathrm{~h}$ after treatment with the compounds isolated from Epimedii Herba for $24 \mathrm{~h}$ in the presence of TCS. The secretion of IL-10, TNF- $\alpha$, and IL-1 $\beta$ were measured using a cytokine ELISA kit (Thermo Fisher Scientific, Waltham, MA, United States).

\section{Measurement of the Effect of the Isolated Compounds on CD206 Expression}

Human monocyte-derived macrophages $\left(2 \times 10^{5}\right.$ cells per well in a 12-well plate) were incubated with the compounds isolated from Epimedii Herba for $24 \mathrm{~h}$ during incubation with IL-4, followed by the determination of CD206 expression by western blot analysis. The lyzed HMDMs were separated on a $10 \%$ sodium dodecyl sulfate (SDS)-polyacrylamide gel 
and transferred to a polyvinylidene fluoride (PVDF) transfer membrane (Millipore, Bedford, MA, United States). The membranes were incubated with an anti-human CD206 antibody (ab125028; Abcam, Cambridge, United Kingdom, $0.1 \mu \mathrm{g} / \mathrm{mL}$ ), followed by visualization with an HRP-conjugated secondary anti-IgG antibody and the enhanced chemiluminescence (ECL) western blotting detection reagent (Thermo Fisher Scientific, Waltham, MA, United States). The membranes were reblotted with an anti- $\beta$-actin antibody as an internal calibration control.

\section{JAK/STAT Activation Assay}

JAK1/STAT3 activation was determined by measuring the increased expression of phosphorylated STAT3 by western blot analysis as described previously (Fujiwara et al., 2011). Briefly, lyzed HMDMs and/or tumor cells were separated on a 10\% SDSpolyacrylamide gel and transferred to a PVDF transfer membrane (Millipore, Bedford, MA, United States). The membranes were incubated with an anti-phosphorylated STAT3 antibody (D3A7; Cell Signaling Technology; 1:2000), an anti-phosphorylated JAK1 antibody (\#3331; Cell Signaling Technology; 1:2000), and an antiSTAT3 antibody (sc-8019; Santa Cruz Biotechnology; 1:2000) (Yokogami et al., 2000; Duan and Simpson-Haidaris, 2006), followed visualization with an HRP-conjugated secondary antiIgG antibody and the ECL western blotting detection reagent (Thermo Fisher Scientific, Waltham, MA, United States). The membranes were reblotted with an anti- $\beta$-actin antibody as an internal calibration control.

\section{Immunohistochemistry}

Paraffin-embedded subcutaneous tumor tissues were sectioned (5 $\mu \mathrm{M}$ thick) and immunostained with pSTAT3, proliferating cell nuclear antigen (PCNA), Iba-1, CD3, CD34, and CD204. Anti-pSTAT3 (D3A7, Cell Signaling Technology; 1:200), antiPCNA (M0879, DAKO; 1:200), anti-Iba-1 (019-19741, Wako; 1:4000), anti-CD3 (413591, Nichirei Biosciences; 1:2), anti-CD34 (ab8129, Abcam; 1:2000), and anti-CD204 (2F8, Invitrogen; 1:2000) antibodies were used as primary antibodies. The sections were subsequently treated with an HRP-conjugated secondary antibody (Nichirei, Tokyo, Japan), followed by the visualization with diaminobenzidine.

\section{Cell Proliferation and Cytotoxicity Assay}

Briefly, $1 \times 10^{4}$ tumor cells (Saos-2 and LM8) were cultured with the Epimedii Herba-derived compounds for $24 \mathrm{~h}$ in a 96-well plate. Cell viability was determined using the WST8 assay (Dojin Chemical, Kumamoto, Japan) according to the manufacturer's protocol.

\section{Co-culture and 5-Bromo-2'-Deoxyuridine (BrdU) Incorporation Assay}

Tumor cells $\left(1 \times 10^{4}\right.$ cells/well $)$ and macrophages stimulated with or without the flavonoid compounds were directly cocultured in 96-well plates for 2 days. 5-Bromo-2'-deoxyuridine (BrdU) incorporation was assayed using a BrdU Cell Proliferation Kit (Roche, Basel, Switzerland) according to the manufacturer's protocol.

\section{Colony Formation Assay}

Tumor cells (100 cells/well) were cultured in RPMI 1640 supplemented with 10\% FBS and SphereMax (Wako) in a 96well ultra-low attachment plate (Corning, NY, United States) for 10 days. The number of colonies (size $>100 \mu \mathrm{M}$ ) was counted under a microscope.

\section{Murine Sarcoma Model}

Female $\mathrm{C} 3 \mathrm{H}$ mice (8-10 weeks old) were purchased from CLEA Japan (Tokyo, Japan). LM8 cells $(5 \times 105$ cells $)$ were suspended in $100 \mu \mathrm{L}$ DMEM culture medium and injected subcutaneously on back of the mice (Day 0$)$. Vehicle ( $0.5 \%$ methylcellulose) or epimedokoreanin B $(20 \mathrm{mg} / \mathrm{kg})$ was administered orally thrice a week. The mice were sacrificed on day 17 and the subcutaneous tumor development and lung metastasis were analyzed. All animal experiments were approved by the Ethics Committee for Animal Experiments of Kumamoto University (Permission Number: A30-047) and were performed in accordance with the Guidelines for Laboratory Animal Experiments.

\section{Statistical Analysis}

All data are representative of two or three independent experiments. Data are expressed as the mean \pm standard deviation (SD). Differences between groups were examined using the Mann-Whitney $U$-test and the non-repeated measures ANOVA to determine the statistical significance. A $p$-value $<0.05$ was considered to be a statistically significant difference.

\section{RESULTS}

\section{Effects of the Crude Extract and Isolated Compounds From Epimedii Herba on Macrophage Activation}

We first examined the effects of a crude extract prepared from Epimedii Herba on IL-10-induced expression of CD163, an M2 phenotype marker, in HMDMs by cell-ELISA. The Epimedii Herba extract significantly inhibited IL-10-induced CD163 expression (Figure 1A). Next, the Epimedii Herba extract was subjected to MCI column chromatography and eluted with $\mathrm{H}_{2} \mathrm{O}$ and $50-100 \% \mathrm{MeOH}$ to obtain three fractions. As shown in Figure 1B, both the $50 \% \mathrm{MeOH}$ fraction and the $100 \%$ $\mathrm{MeOH}$ fraction significantly suppressed the CD163 expression, suggesting that these fractions contained compound(s) that could inhibit CD163 expression. Therefore, we isolated the compounds from these fractions and identified them as icariin, icariside II, limonianin, epimedokoreanin B, icariside I, and epimedoside C (Figure 2). Icariin, a flavonoid glycoside, is the main constituent in the $\mathrm{MeOH}$-eluted fractions, as shown in Figures 3A,B. Because the sugar chains of glycosides such as icariin, icariside II, icariside $\mathrm{I}$, and epimedoside $\mathrm{C}$ are degraded by the action of intestinal bacteria after oral administration, the aglycons such as icaritin and desmethylicaritin (Figure 2) can be assumed to act as the physiologically active compounds (Kida et al., 1997; Hasegawa and Uchiyama, 1998). 
A

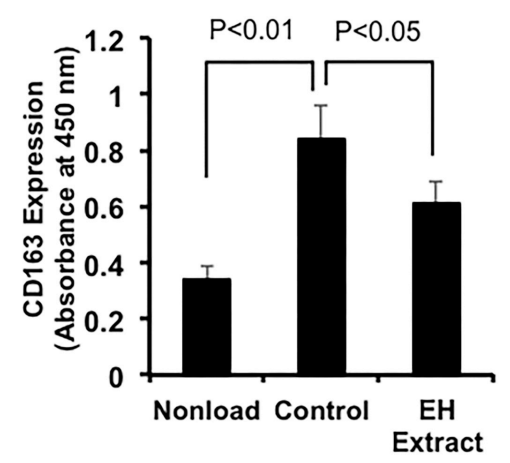

B

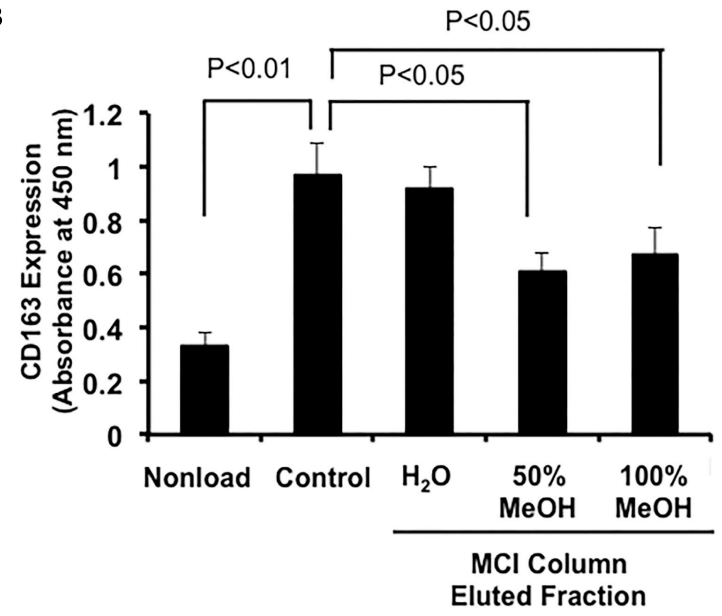

FIGURE 1 | Effects of extract prepared from Epimedii Herba on IL-10-induced CD163 expression in human macrophages. (A) HMDMs $\left(5 \times 10^{4}\right.$ cells per well in 96-well plates) were incubated with Epimedii Herba extract $(200 \mu \mathrm{g} / \mathrm{mL})$ in the presence of IL-10 (20 ng/mL) for $24 \mathrm{~h}$, followed by the determination of CD163 expression using cell-ELISA. (B) HMDMs

$\left(5 \times 10^{4}\right.$ cells per well in 96-well plates) were incubated with $\mathrm{H}_{2} \mathrm{O}$-eluted and $\mathrm{MeOH}$-eluted fractions prepared from the Epimedii Herba extract $(200 \mu \mathrm{g} / \mathrm{mL})$ in the presence of IL-10 (20 ng/mL) for $24 \mathrm{~h}$. CD163 expression was then determined using cell-ELISA. The data are presented as mean $\pm \mathrm{SD}$.

Therefore, we examined the effects of these compounds (Figure 2) on CD163 expression in HMDMs. We found that limonianin, epimedokoreanin B, icaritin, and desmethylicaritin inhibited IL-10-induced CD163 expression (Figure 4A), while they had no cytotoxic effect on the macrophages (Figure 4B), suggesting that aglycons are the active compounds in this study. Therefore, we chose to use limonianin, epimedokoreanin B, icaritin, and desmethylicaritin for further evaluations.

Next, we measured the effect of limonianin, epimedokoreanin $\mathrm{B}$, icaritin, and desmethylicaritin on the secretion of IL-10, TNF- $\alpha$, and IL- $1 \beta$ from HMDMs induced by TCS stimulation. TCS stimulation increased IL-10 secretion, a cytokine marker of M2 macrophages, and decreased TNF- $\alpha$ and IL- $1 \beta$ secretion, cytokine markers of M1 macrophages, in HMDMs (Figure 4C). Under the assay conditions employed, the tested compounds significantly inhibited TCS-induced IL-10 secretion (Figure 4C). In addition, epimedokoreanin B also enhanced TNF- $\alpha$ and
IL-1 $\beta$ secretion reduced by TCS stimulation (Figure 4C). Furthermore, epimedokoreanin B also inhibited IL-4-induced CD206 expression, another M2 phenotype marker (Figure 4D). These data indicate that epimedokoreanin B has a potentially inhibitory effect on M2 polarization of HMDMs.

\section{Effect of Limonianin, Epimedokoreanin $B$, Icaritin, and Desmethylicaritin on STAT3 Activation in Macrophages}

Since the activation of STAT3 contributes to the M2 polarization of macrophages (Mantovani et al., 2002), we next examined the effect of limonianin, epimedokoreanin B, icaritin, and desmethylicaritin on IL-10-induced JAK1/STAT3 activation in HMDMs. As shown in Figure 4E, IL-10 induced JAK1/STAT3 activation in HMDMs. Under the assay conditions employed, epimedokoreanin B significantly suppressed IL10-induced JAK1/STAT3 activation. These results suggest that epimedokoreanin B regulates conversion of M2 into M1 phenotype in HMDMs by inhibiting STAT3 activation.

\section{Effect of Limonianin, Epimedokoreanin $B$, Icaritin, and Desmethylicaritin on STAT3 Activation and Proliferation in Tumor Cells}

It is well known that the activation of STAT3 is critically associated with tumorigenesis (Thoennissen et al., 2009), and STAT3 is considered an important target for anticancer therapy (Iwamaru et al., 2007; Fuh et al., 2009). Therefore, we investigated the effect of limonianin, epimedokoreanin B, icaritin, and desmethylicaritin on the proliferation of Saos2 human osteosarcoma cells and LM8 mouse sarcoma cells. As shown in Figure $\mathbf{5 A}$, epimedokoreanin B, icaritin, and desmethylicaritin significantly inhibited the proliferation of Saos- 2 cells. Among these compounds, epimedokoreanin B had a strong inhibitory effect on Saos-2 cell proliferation. Epimedokoreanin B also significantly inhibited the proliferation of LM8 cells (Figure 5B). Furthermore, epimedokoreanin B also inhibited colony formation in both Saos-2 and LM-8 cells (Figure 5C). As shown in Figures 5D,E, STAT3 was constantly activated in both cell lines. Under the assay conditions used, epimedokoreanin B also suppressed STAT3 activation in both Saos- 2 cells and LM8 cells (Figures 5D,E). These data suggest that inhibition of STAT3-related signal pathway by epimedokoreanin B suppresses tumor cell proliferation.

\section{Effect of Epimedokoreanin B on Tumor Proliferation Under Co-culture Conditions With Macrophages and Sarcoma Cells}

Epimedokoreanin B also suppressed TCS-induced STAT3 activation in mouse peritoneal macrophages (Figure 6A). On the other hand, limonianin had no effect on TCS-induced STAT3 activation (Figure 6A). These data suggest that epimedokoreanin $B$ regulates macrophage activation in both human and mouse macrophages. We next tested whether the macrophages 


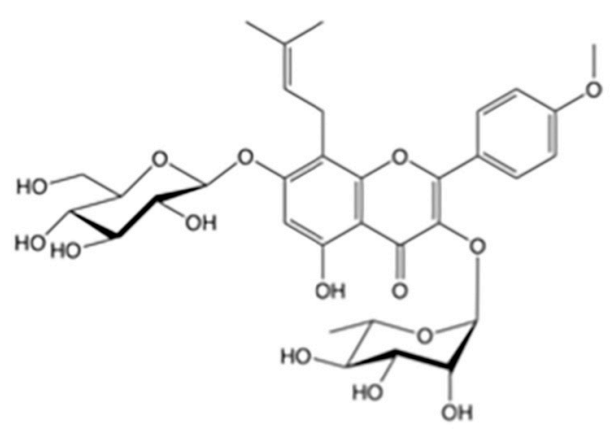

Icariin<smiles></smiles>

Icariside II<smiles>CC1(C)C=Cc2c(cc(O)c3c(=O)cc(-c4ccc(O)cc4)oc23)O1</smiles><smiles>CC(C)=CCc1cc(-c2cc(=O)c3c(O)cc(O)c(CC=C(C)C)c3o2)cc(O)c1O</smiles>

Epimedokoreanin B<smiles>COc1ccc(-c2oc3c(CC=C(C)C)c(OC4OC(CO)C(O)[C@H](O)[C@H](O)C4O)cc(O)c3c(=O)c2O)cc1</smiles>

Icariside I<smiles>CC(C)=CCc1c(OC2OC(CO)C(O)C(O)C(O)C2O)cc(O)c2c(=O)c(O)c(-c3ccc(O)cc3)oc12</smiles>

Epimedoside C<smiles>COc1ccc(-c2oc3c(CC=C(C)C)c(O)cc(O)c3c(=O)c2O)cc1</smiles>

Icaritin<smiles>CC(C)=CCc1c(O)cc(O)c2c(=O)c(O)c(-c3ccc(O)cc3)oc12</smiles>

Desmethylicaritin

FIGURE 2 | Chemical structure of compounds derived from Epimedii Herba.

treated with the flavonoid compounds (epimedokoreanin $\mathrm{B}$ and limonianin) inhibit sarcoma cell proliferation in a co-culture study using mouse macrophages and the LM8 mouse sarcoma cell line. Mouse peritoneal macrophages and mouse LM8 sarcoma cells were co-cultured, and the BrdU incorporation assay was performed, as shown in Figure 6B. Co-culture with macrophages enhanced tumor cell proliferation (Figure 6B). This enhanced effect was reduced by co-culture with epimedokoreanin B-treated macrophages (Figure 6B), indicating that epimedokoreanin B suppresses tumor proliferation by regulating macrophage activation.

\section{Epimedokoreanin B Suppressed Subcutaneous Tumor Development}

To verify the antitumor effects of epimedokoreanin B in an in vivo study, we next investigated the effects of epimedokoreanin B in a mouse tumor model. Epimedokoreanin $\mathrm{B}$ was administered orally after the subcutaneous injection of LM8 cells in $\mathrm{C} 3 \mathrm{H}$ mice, as shown in Figure 7A. On day 17 following tumor injection, subcutaneous tumors $(>10 \mathrm{~mm})$ were detected in all the control mice. On the other hand, epimedokoreanin $\mathrm{B}$ significantly inhibited 


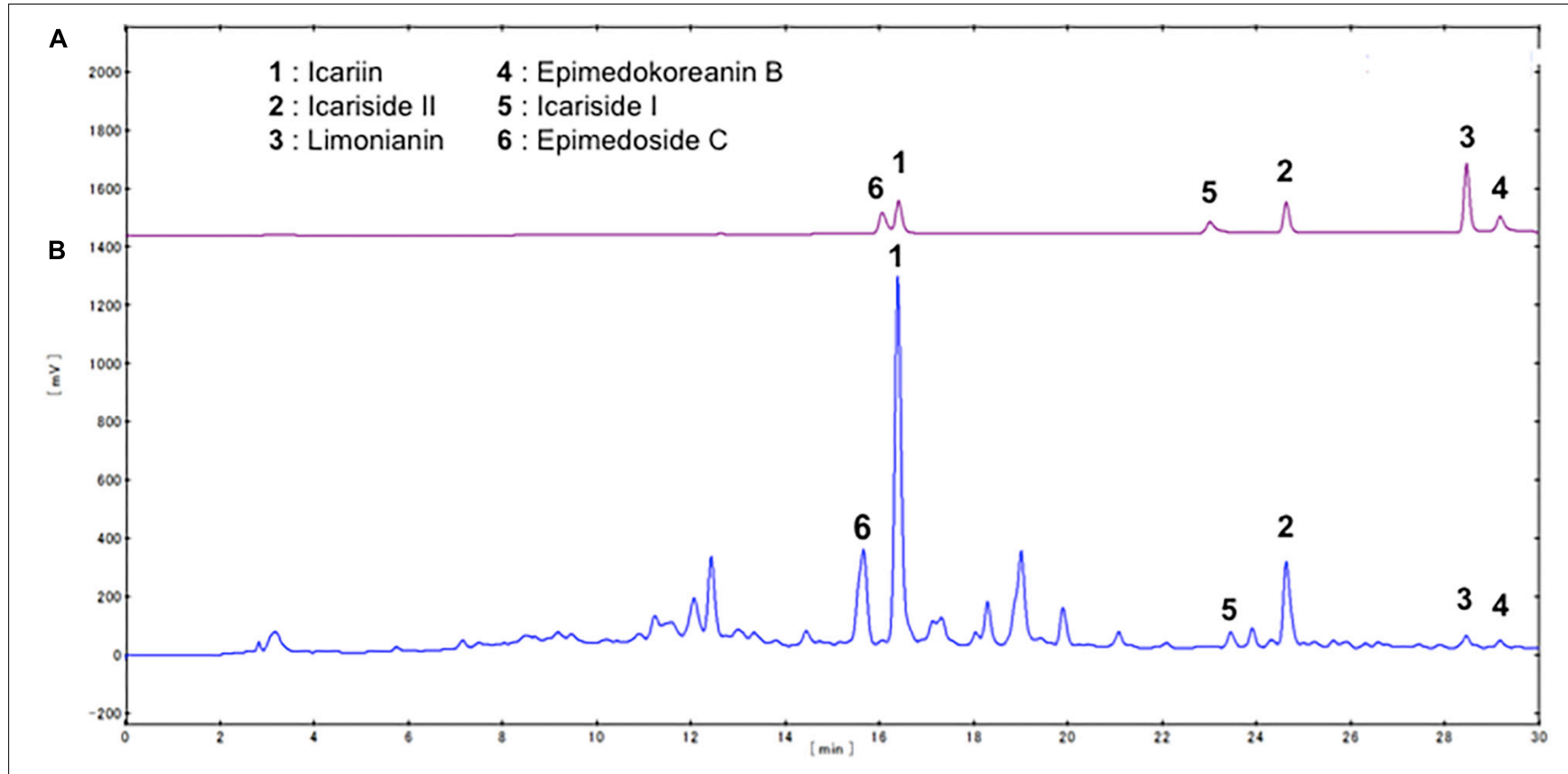

FIGURE 3 | HPLC profile of compounds contained in Epimedii Herba. (A) HPLC analysis of the standard compounds isolated from Epimedii Herba. (B) HPLC profile of the fraction prepared using $\mathrm{MCl}$ gel CHP-20P (eluted with $\mathrm{MeOH}$ ).

subcutaneous tumor development (Figure 7B). We next performed immunohistochemical studies to examine the effects of epimedokoreanin B on the subcutaneous tumor cells. Tumor cell proliferation was evaluated by immunostaining for PCNA, and angiogenesis was evaluated by immunostaining for CD34. Both PCNA and CD34 expression was reduced following treatment with epimedokoreanin B (Figure 7C). STAT3 activation in the subcutaneous tumor tissue was also reduced following epimedokoreanin $\mathrm{B}$ administration (Figure 7C). However, the numbers of Iba-1-positive macrophages (pan-macrophages), CD204-positive macrophages (M2-like macrophages), CD3-positive lymphocytes, CD4positive lymphocytes, and CD8-positive lymphocytes in subcutaneous tumor tissue remained unchanged following epimedokoreanin B administration (Figures 8A,B). However, the ratio of CD204-positive cells to Iba-1-positive cells decreased in response to epimedokoreanin B administration. These data indicate that epimedokoreanin B also inhibits tumor development in a mouse model by suppressing STAT3 activation.

\section{DISCUSSION}

Flavonoid compounds from Epimedii Herba have been shown to have various activities. Desmethylicaritin has an inhibitory effect on LPS-induced NO production in murine macrophages by suppressing iNOS activity (Chen et al., 2008) and an inhibitory effect on tumor proliferation in U87MG human glioblastoma cells (Kang et al., 2016). In the present study, desmethylicaritin inhibited the proliferation of Saos-2 cells (Figure 5A). It has been reported that icaritin has anti-inflammatory effects on mouse peritoneal macrophages by suppressing both p38 and JNK activation (Lai et al., 2013) and that it exerts antitumor and anti-inflammatory effects by modulating the function of myeloid-derived suppressive cells (MDSCs) (Zhou et al., 2011). However, there are limited number of reports on the biological activities of limonianin and epimedokoreanin B. We believe that this is the first report describing the antitumor effect of epimedokoreanin B both in vitro and in vivo.

In the present study, CD163 was used to evaluate M2 polarization in HMDMs. CD163 is a well-documented marker for detecting M2-like macrophages in paraffinembedded surgical specimens (Komohara et al., 2006). In clinicopathological studies of malignant tumors using CD163 to detect M2-like TAMs, patients with glioma (Komohara et al., 2011b), follicular lymphoma (Clear et al., 2010), renal cancer (Komohara et al., 2011a), and pancreatic cancer (Kurahara et al., 2011) were shown to have poorer clinical prognosis in the presence of TAMs with a higher expression of CD163. CD163 is a member of the scavenger receptor cysteine-rich protein superfamily. It binds the hemoglobin-haptoglobin ( $\mathrm{Hb}-\mathrm{Hp}$ ) complex (Kristiansen et al., 2001) and subsequently induces IL-10 secretion and HO-1 expression (Philippidis et al., 2003), which suggests that CD163 contributes to immunosuppression. Therefore, inhibition of TAM polarization to a CD163-positive M2 phenotype is a probable therapeutic strategy for cancer. In our previous studies, several compounds that suppress the polarization of macrophages to the CD163-positive M2 phenotype were discovered using an established screening 


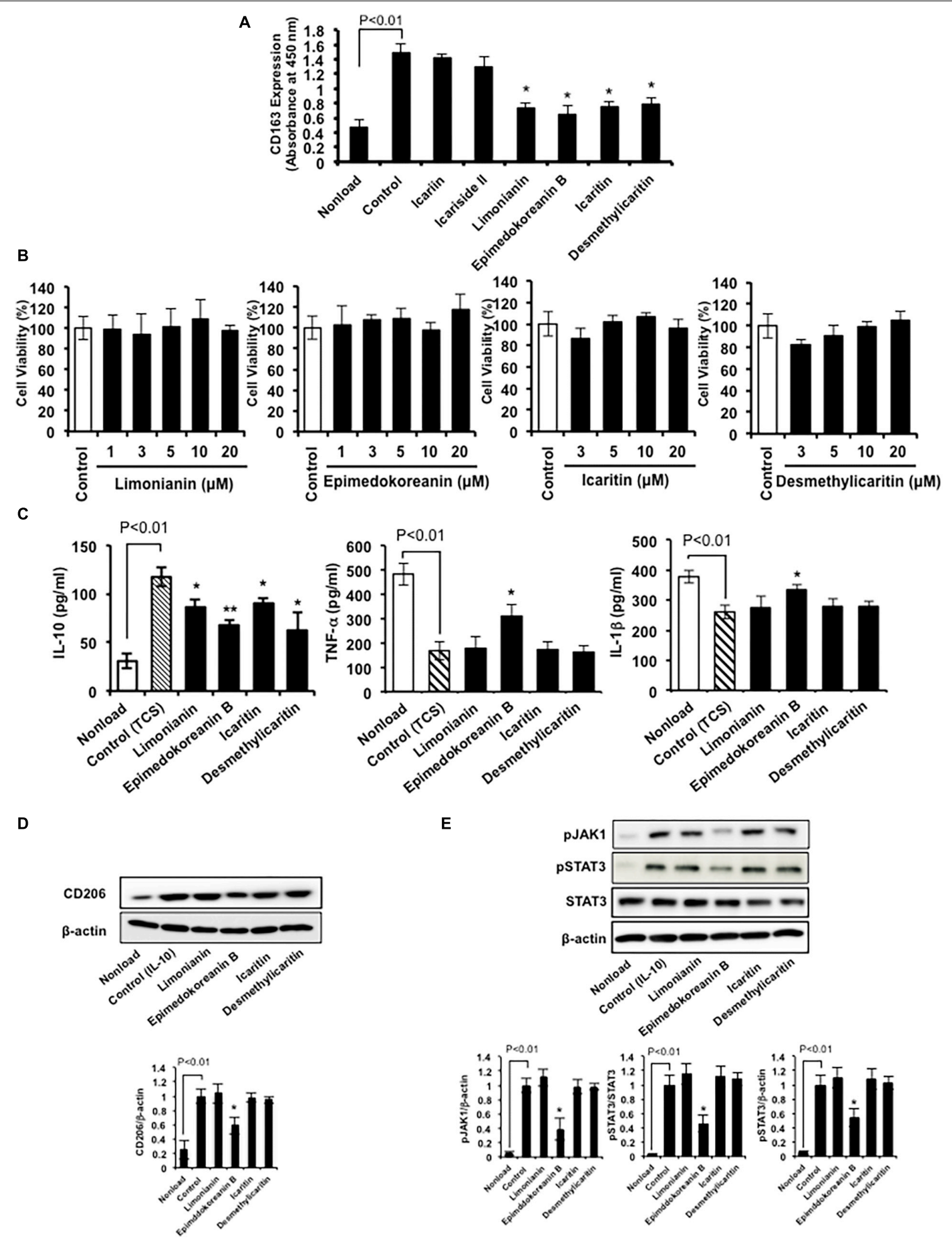

FIGURE 4 | Effects of compounds isolated from Epimedii Herba on macrophage activation. (A) HMDMs were incubated with compounds (5 $\mu$ M) in the presence of IL-10 (20 ng/mL) for $24 \mathrm{~h}$, followed by measurement of CD163 expression using cell-ELISA. (B) HMDMs were incubated with the indicated concentrations of the four flavonoid compounds for $24 \mathrm{~h}$, followed by the determination of cell viability using WST-8 assay. (C) HMDMs were incubated with the four flavonoid compounds $(5 \mu \mathrm{M})$ for $24 \mathrm{~h}$ in the presence of tumor culture supernatant (TCS), followed by the determination of IL-10, TNF- $\alpha$, and IL- $1 \beta$ secretion by ELISA. (D) HMDMs were incubated with flavonoid compounds $(5 \mu \mathrm{M})$ in the presence of IL-4 $(20 \mathrm{nM})$ for $24 \mathrm{~h}$, followed by the determination of CD206 and $\beta$-actin protein expression by western blot analysis. (E) HMDMs were incubated with the four flavonoid compounds $(5 \mu \mathrm{M})$ in the presence of IL-10 (20 nM) for $6 \mathrm{~h}$, followed by the determination of phosphorylated JAK1, phosphorylated STAT3, STAT3, and $\beta$-actin protein expression by western blot analysis. Experiments ware repeated three times with almost identical results. The data are presented as mean \pm SD. ${ }^{*} p<0.05,{ }^{* *} p<0.01$ vs. control. 

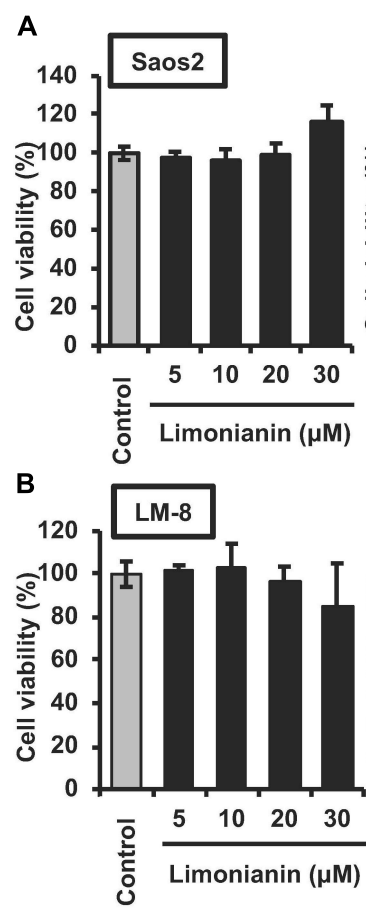
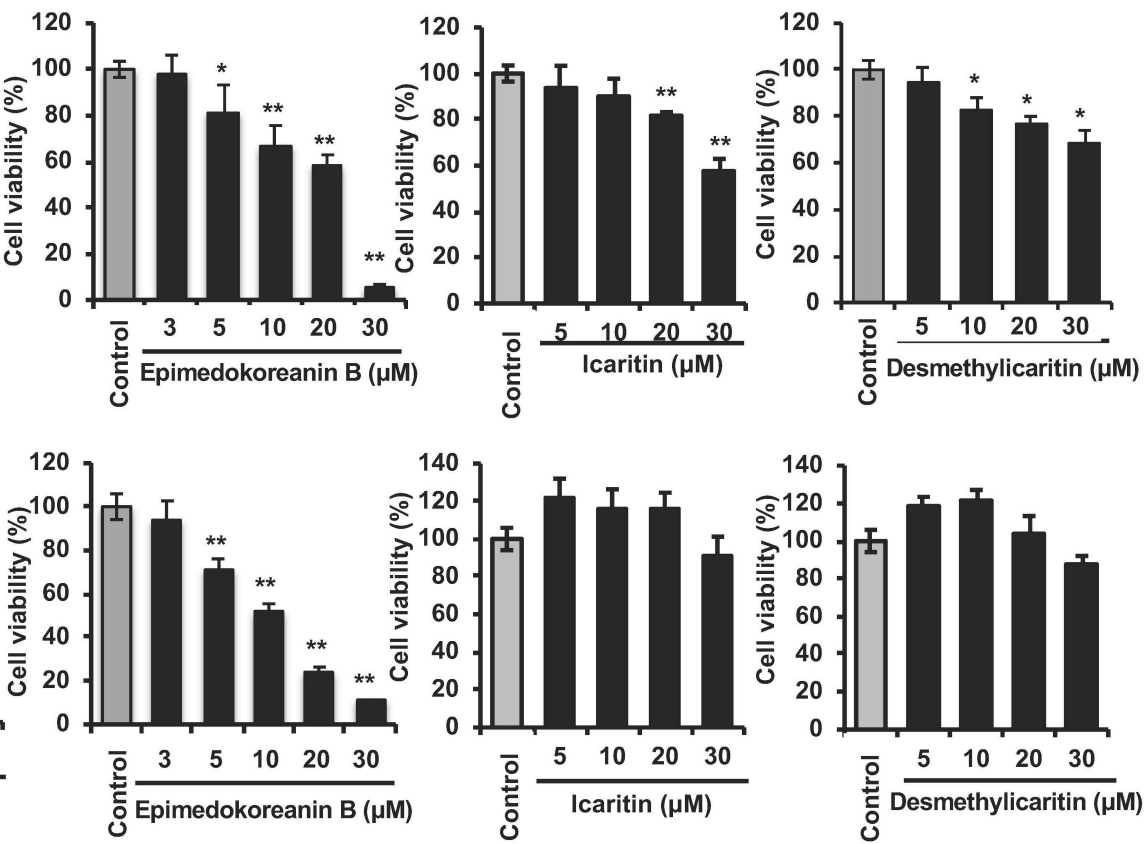

C
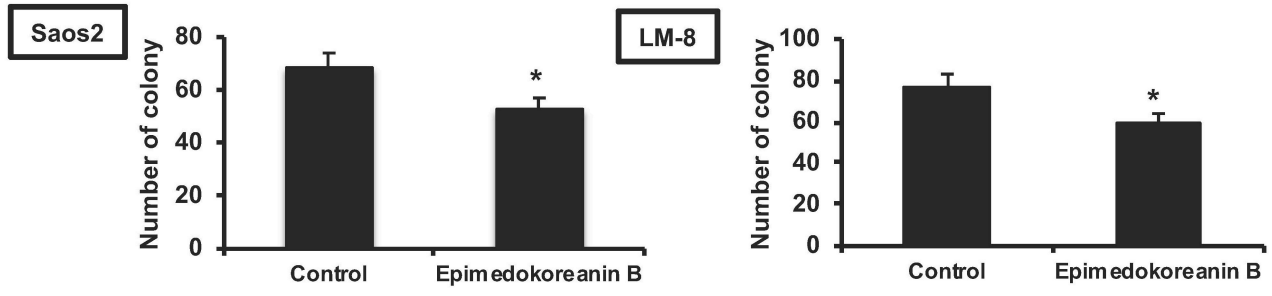

D

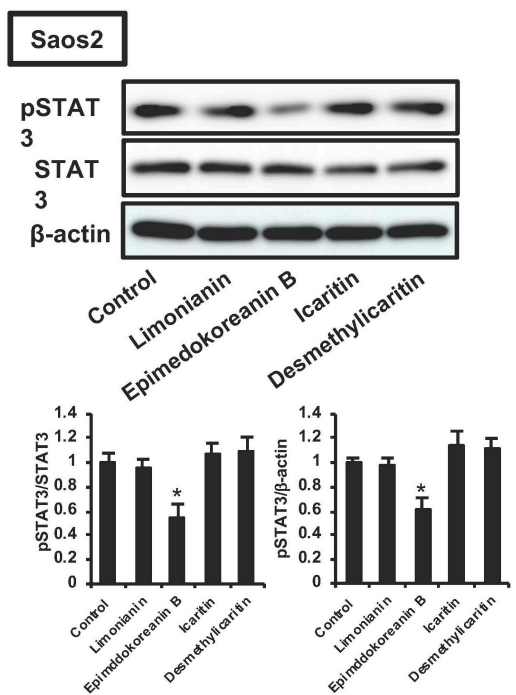

E

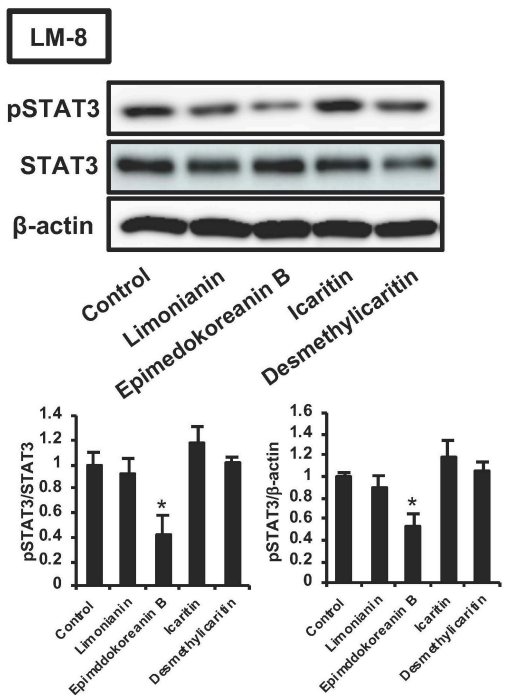

FIGURE 5 | Effects of compounds isolated from Epimedii Herba on STAT3 activation and proliferation in tumor cells. Saos-2 human osteosarcoma cells (A) and LM8 mouse sarcoma cells (B) were incubated with the indicated concentrations of the four flavonoid compounds for $24 \mathrm{~h}$, followed by determination of cell viability using the WST-8 assay. (C) Tumor cells were incubated with epimedokoreanin B (5 $\mu$ M) for 10 days in the presence of SphereMax, followed by determination of the number of colonies under a microscope. Saos-2 human osteosarcoma cells (D) and LM8 mouse sarcoma cells (E) were incubated with flavonoid compounds $(10 \mu \mathrm{M})$ for $24 \mathrm{~h}$. The expression of phosphorylated STAT3, STAT3, and $\beta$-actin was determined by western blot analysis. Experiments ware repeated three times with almost identical results. The data are presented as mean $\pm \mathrm{SD}$. ${ }^{*} p<0.01,{ }^{* *} p<0.005$ vs. control. 
A

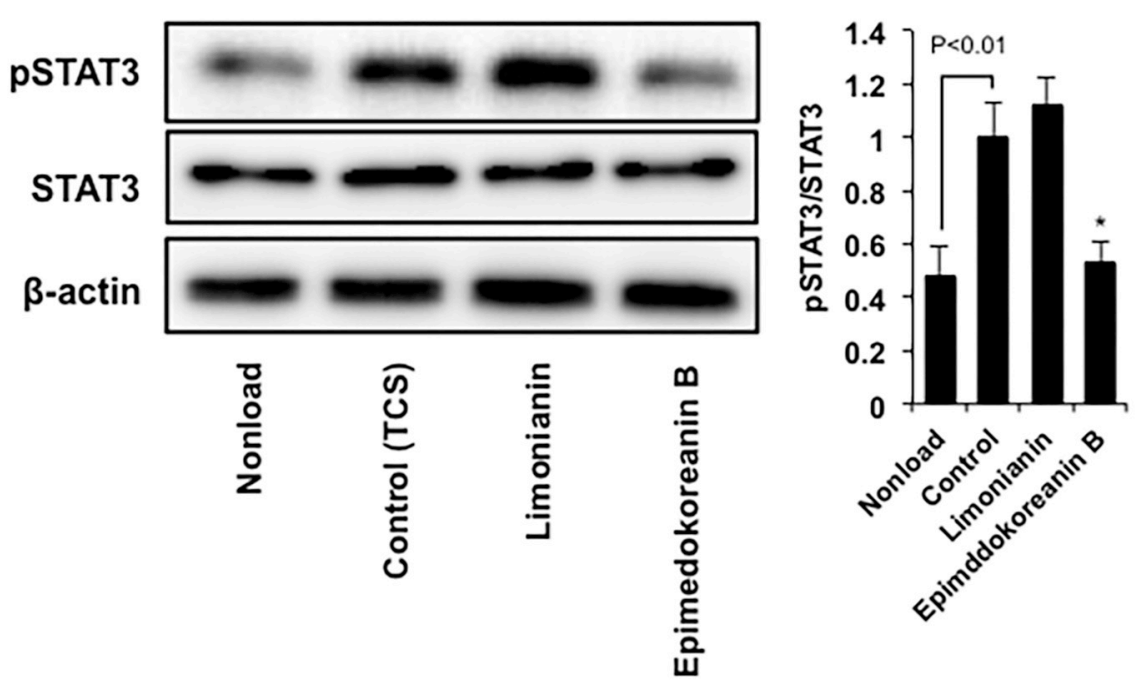

B

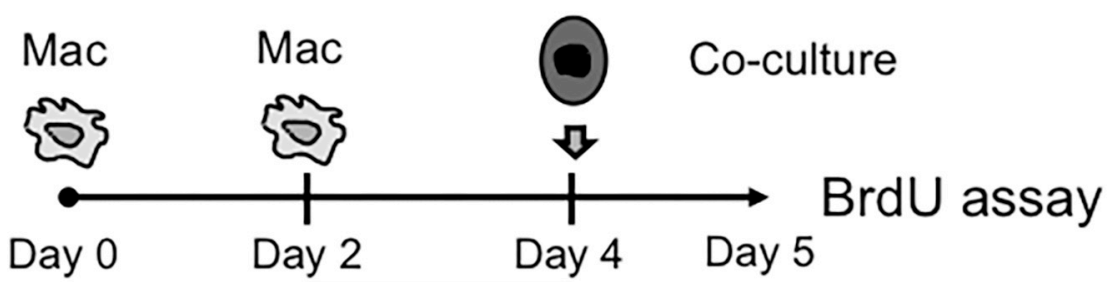

Epimedokoreanin B (EKB)

Limonianin (LMN)
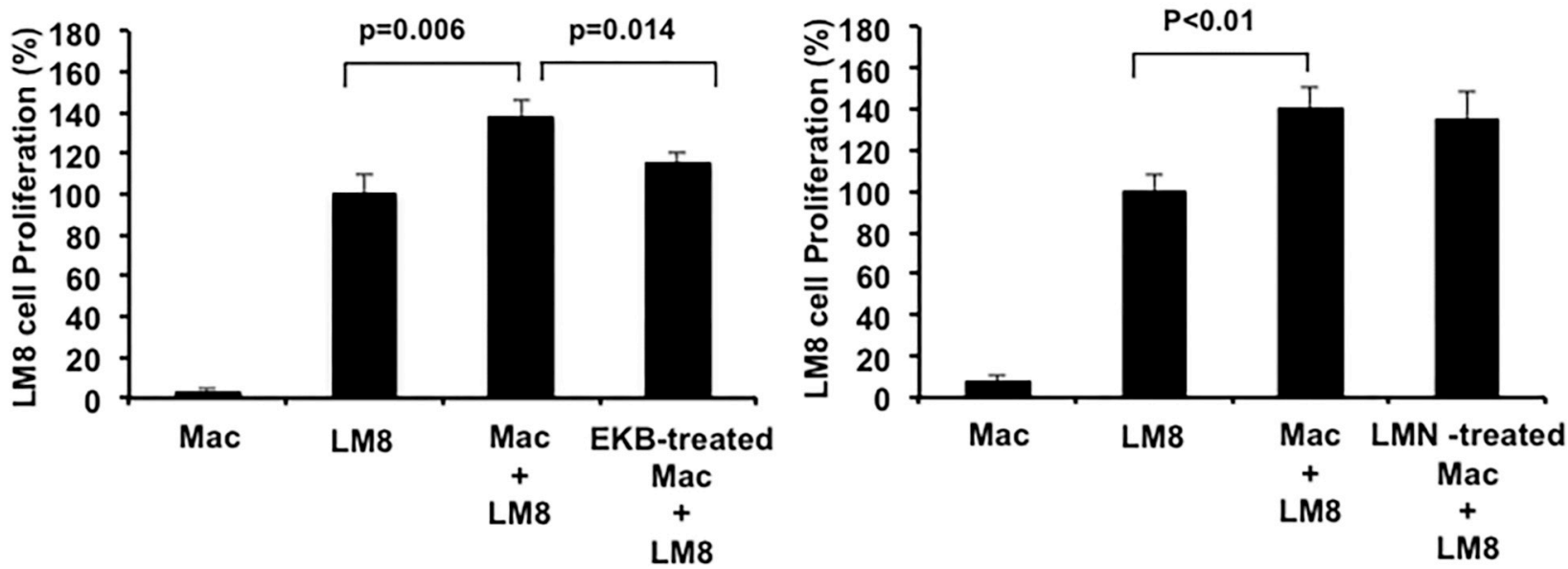

FIGURE 6 | Effect of epimedokoreanin B on cell-cell interactions between mouse macrophages and mouse sarcoma cell line. (A) Mouse peritoneal macrophages were incubated with epimedokoreanin B $(5 \mu \mathrm{M})$ and limonianin $(5 \mu \mathrm{M})$ in the presence of TCS from LM8 cells for $6 \mathrm{~h}$. The expression of phosphorylated STAT3, STAT3, and $\beta$-actin was determined by western blot analysis. (B) Mouse peritoneal macrophages were incubated with LM8 sarcoma cells under direct co-culture conditions for $24 \mathrm{~h}$ after stimulation with epimedokoreanin $\mathrm{B}(3 \mu \mathrm{M})$ and limonianin $(3 \mu \mathrm{M})$ for 2 days, followed by the determination of proliferation by the BrdU incorporation assay. Experiments ware repeated three times with almost identical results. The data are presented as mean $\pm \mathrm{SD}$. ${ }^{*} p<0.05$ vs. control. 
A

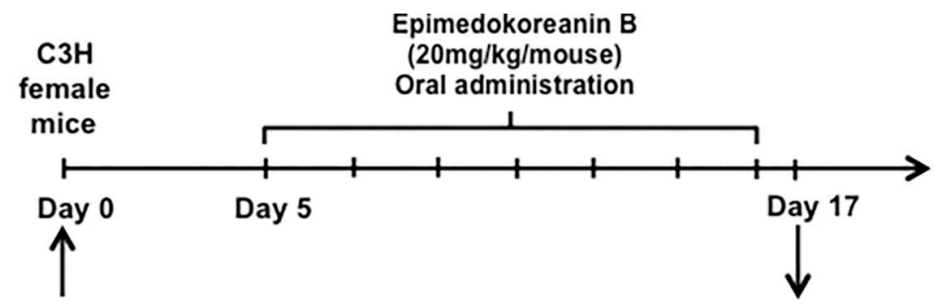

LM-8 cells injection
Tissue sampling

B
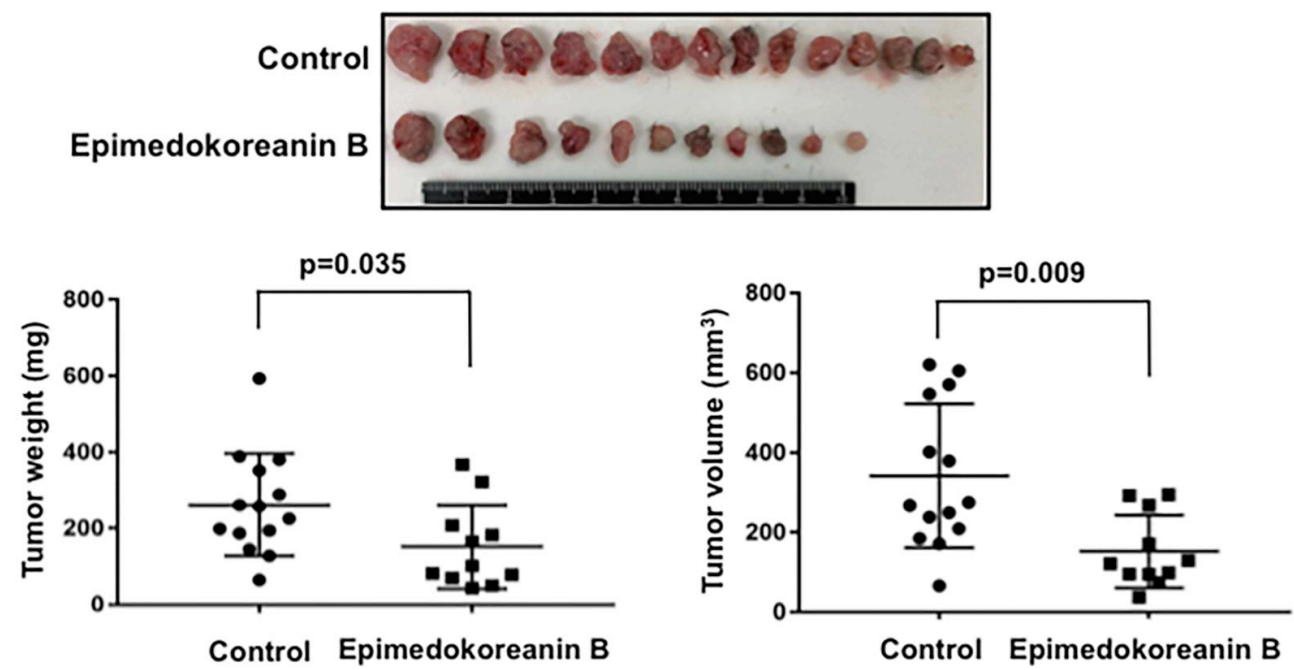

C
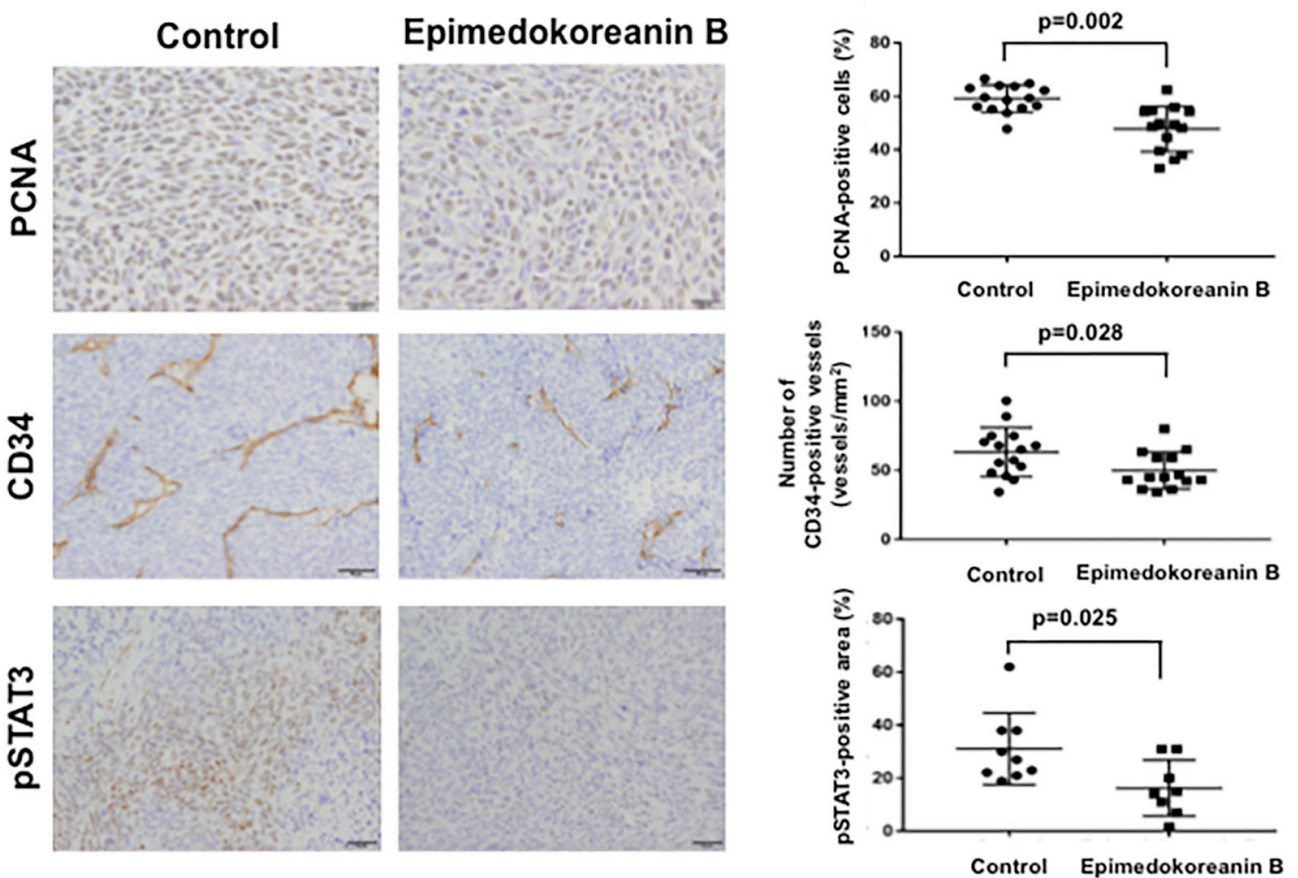

FIGURE 7 | Effect of epimedokoreanin B on tumor progression in LM8 cell-injected mice. Epimedokoreanin B (20 mg/kg) was administered to mice injected with LM8 cells as described in the procedure (A), followed by the determination of subcutaneous tumor weights (B). PCNA expression, CD34 expression, and STAT3 activation in subcutaneous tumor tissues were evaluated by immunostaining (C). 
A
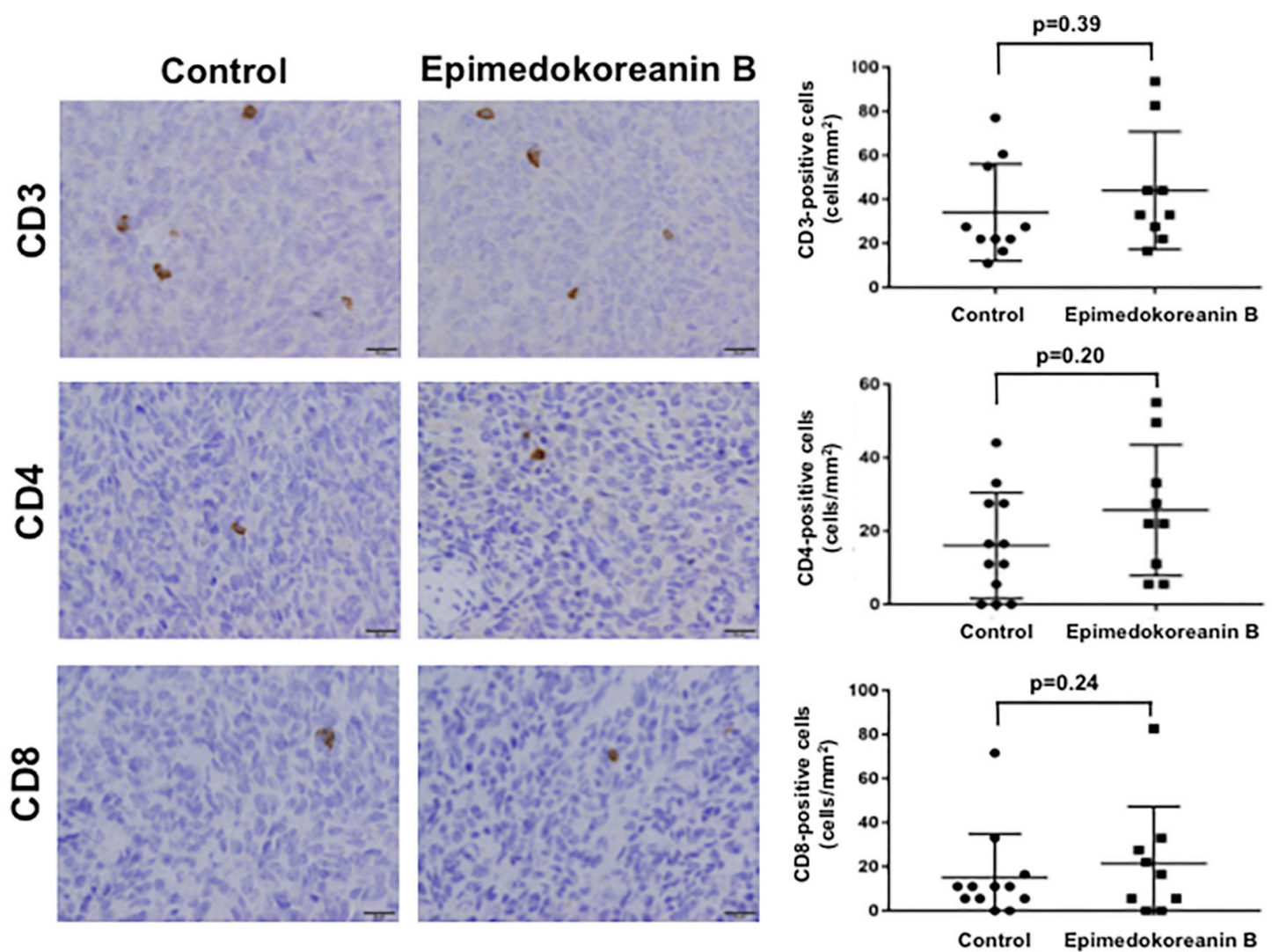

B
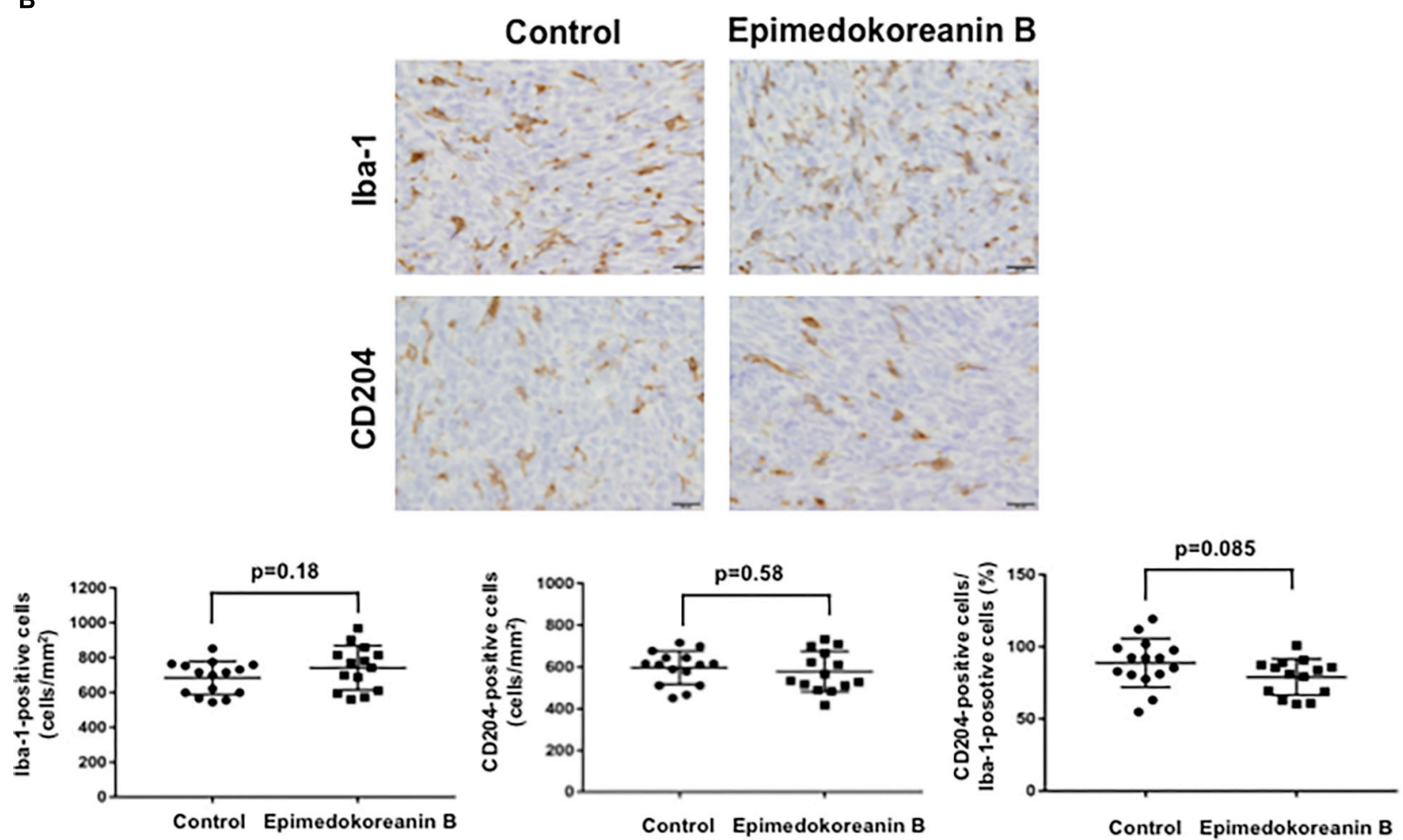

FIGURE 8 | Number of lymphocytes and macrophages in tumor tissue. (A) $\mathrm{CD}^{+}, \mathrm{CD}^{+}$, and $\mathrm{CD} 8^{+}$lymphocytes in subcutaneous tumor tissues evaluated by immunostaining. (B) lba-1- and CD204-positive macrophages in subcutaneous tumor tissues were evaluated by immunostaining. 
system based on CD163-specific cell-ELISA. Corosolic acid and onionin A inhibit tumor proliferation by suppressing M2 polarization of macrophages as shown in in vitro and in vivo studies (Fujiwara et al., 2011, 2016; Horlad et al., 2013; Tsuboki et al., 2016). We also recently reported that the expression of CD163 on macrophages is associated with poor prognosis in undifferentiated human pleomorphic sarcoma. CD163 promotes murine sarcoma progression by inducing IL-6 secretion (Shiraishi et al., 2018), which indicates the pro-tumorigenic role of TAMs expressing CD163 in sarcoma. In the present study, we demonstrated that four flavonoid compounds isolated from Epimedii Herba inhibited M2 marker expression (CD163 and IL-10) in HMDMs (Figures 4A,C), while having no cytotoxic effect on these cells (Figure 4B).

We also demonstrated that limonianin and epimedokoreanin $B$ inhibited IL-10-induced STAT3 activation in HMDMs (Figure 4D). It is known that the excessive activation of STAT3 in tumor cells is associated with poor prognosis, and IL-6, a classic STAT3-activator produced by mesenchymal stem cells, induces STAT3 activation in tumor cells such as Saos-2 osteosarcoma cells and consequently promotes tumor proliferation and metastasis ( $\mathrm{Tu}$ et al., 2012). It was recently reported that $\mathrm{CD} 163$-positive macrophages are also associated with both proliferation in Saos- 2 cells and tumor progression in a sarcoma-bearing mouse model by IL-6-induced STAT3 activation (Shiraishi et al., 2018). Epimedokoreanin B showed an inhibitory effect on STAT3 activation in both macrophages and tumor cells (Figures 4D, 5C,D), and epimedokoreanin B suppressed tumor progression in the LM8 tumor-bearing mouse model in the present study (Figure 7B). Furthermore, administration of epimedokoreanin B significantly decreased both pSTAT3-positive area and PCNA-positive cells in subcutaneous tumor tissues (Figure 7C), thus indicating that epimedokoreanin B suppresses tumor development in a mouse model by inhibiting STAT3 activation in both macrophages and tumor cells. STAT3 is a known M2 phenotype-inducer in macrophages. As shown in Figure 8, epimedokoreanin $\mathrm{B}$ reduced the ratio of $\mathrm{CD} 204^{+} \mathrm{M} 2$ macrophages to Iba$1^{+}$total macrophages in the subcutaneous tumor tissues. However, there was no significant effect on M2-polarization in the in vivo mouse model in the present study. The reason for this discrepancy may be the differences in sensitivity of humans and mice to these compounds. Since lack of M2related genes such as that coding CD163 was seen in mouse TAMs (Shiraishi et al., 2018), the differences in the gene expression profiles between humans and mice may also cause this discrepancy.

In several human tumors, a STAT3 inhibitor rescued the expression of proinflammatory cytokines and costimulatory molecules on TAMs and peripheral macrophages and resulted in the enhancement of immune responses (Hussain et al., 2007), thus indicating the significance of STAT3 activation in cell-cell interactions between TAMs and tumor cells. STAT3 is involved not only in macrophage differentiation but also in tumor cell proliferation (Yu et al., 2007). Activation of STAT3 in glioma cells is closely correlated with poor clinical prognoses in patients with grade III glioma (Abou-Ghazal et al., 2008). Therefore, STAT3 is considered to be a target molecule in several tumor types (Brantley and Benveniste, 2008). Furthermore, the activation of STAT3 in tumor cells was reported to cause resistance to anticancer therapies, such as radiotherapy and chemotherapy (Gao et al., 2010).

Niclosamide, a selective STAT3 inhibitor, had a stronger inhibitory effect on STAT3 activation compared to epimedokoreanin B (Supplementary Figure S1). However, niclosamide affected the vitality of human macrophages, thus suggesting that direct STAT3 targeting agents may have undesirable side effect on macrophages (Supplementary Figure S1). It is known that natural compound-derived STAT3 inhibitors such as curcumin and butein are non-specific and target STAT3 indirectly. We believe that epimedokoreanin B also targets STAT3 indirectly.

We also previously revealed that natural compound-derived STAT3 inhibitors, such as corosolic acid and onionin A, enhanced the efficacy of chemotherapeutic agents against tumor cells (Fujiwara et al., 2013, 2014). In the present study, we revealed that epimedokoreanin B significantly inhibited STAT3 activation in human macrophages and tumor cells and suppressed macrophage polarization to the M2 phenotype. In addition, the oral administration of epimedokoreanin B significantly suppressed tumor development in tumorbearing mice.

These findings indicate that epimedokoreanin $\mathrm{B}$ is a functional compound for antitumor therapy that regulates macrophage activation and tumor proliferation. Epimedokoreanin B may also directly suppress tumor proliferation and enhance tumor sensitivity to radiotherapy and chemotherapy. Therefore, epimedokoreanin B may be a useful compound for anticancer therapy, and the products derived from Epimedii Herba may be useful for tumor prevention.

\section{DATA AVAILABILITY STATEMENT}

All datasets generated for this study are included in the article/Supplementary Material.

\section{ETHICS STATEMENT}

All protocols using human materials were approved by the Kumamoto University Review Board (No. 486) and were conducted in accordance with the approved guidelines. All animal experiments were approved by the Ethics Committee for Animal Experiments of Kumamoto University (Permission Number: A30-047) and were performed in accordance with the Guidelines for Laboratory Animal Experiments. 


\section{AUTHOR CONTRIBUTIONS}

YF and YK designed the experiments. CP, YF, HH, DS, TIr, JT, and TIk analyzed the data. CP, YF, and YK wrote the manuscript. CP, YF, HH, and DS performed the experiments. All authors critically reviewed and approved the final form of the manuscript.

\section{FUNDING}

This work was supported by JSPS KAKENHI (Grant Numbers 16K09247, 16K10865, 19K09555, 19K08603, and 19K18699).

\section{REFERENCES}

Abou-Ghazal, M., Yang, D. S., Qiao, W., Reina-Ortiz, C., Wei, J., Kong, L. Y., et al. (2008). The incidence, correlation with tumor-infiltrating inflammation, and prognosis of phosphorylated STAT3 expression in human gliomas. Clin. Cancer Res. 14, 8228-8235. doi: 10.1158/1078-0432.CCR-08-1329

Bacher, M., Brader, G., Greger, H., and Hofer, O. (2010). Complete $1 \mathrm{H}$ and $13 \mathrm{C}$ NMR data assignment of new constituents from Severinia buxifolia. Magn. Reson. Chem. 48, 83-88. doi: 10.1002/mrc.2548

Brantley, E. C., and Benveniste, E. N. (2008). Signal transducer and activator of transcription-3: a molecular hub for signaling pathways in gliomas. Mol. Cancer Res. 6, 675-684. doi: 10.1158/1541-7786.MCR-07-2180

Chen, C. C., Tsai, P. C., Wei, B. L., and Chiou, W. F. (2008). 8-Prenylkaempferol suppresses inducible nitric oxide synthase expression through interfering with JNK-mediated AP-1 pathway in murine macrophages. Eur. J. Pharmacol. 590, 430-436. doi: 10.1016/j.ejphar.2008.05.018

Clear, A. J., Lee, A. M., Calaminici, M., Ramsay, A. G., Morris, K. J., Hallam, S., et al. (2010). Increased angiogenic sprouting in poor prognosis FL is associated with elevated numbers of $\mathrm{CD} 163+$ macrophages within the immediate sprouting microenvironment. Blood 115, 5053-5056. doi: 10.1182/ blood-2009-11-253260

Duan, H. O., and Simpson-Haidaris, P. J. (2006). Cell type-specific differential induction of the human gamma-fibrinogen promoter by interleukin-6. J. Biol. Chem. 281, 12451-12457. doi: 10.1074/jbc.M600294200

Espinosa, I., Beck, A. H., Lee, C. H., Zhu, S., Montgomery, K. D., Marinelli, R. J., et al. (2009). Coordinate expression of colony-stimulating factor-1 and colony-stimulating factor-1-related proteins is associated with poor prognosis in gynecological and nongynecological leiomyosarcoma. Am. J. Pathol. 174, 2347-2356. doi: 10.2353/ajpath.2009.081037

Fuh, B., Sobo, M., Cen, L., Josiah, D., Hutzen, B., Cisek, K., et al. (2009). LLL3 inhibits STAT3 activity, suppresses glioblastoma cell growth and prolongs survival in a mouse glioblastoma model. Br. J. Cancer 100, 106-112. doi: 10. 1038/sj.bjc.6604793

Fujiwara, Y., Horlad, H., Shiraishi, D., Tsuboki, J., Kudo, R., Ikeda, T., et al. (2016). Onionin A, a sulfur-containing compound isolated from onions, impairs tumor development and lung metastasis by inhibiting the protumoral and immunosuppressive functions of myeloid cells. Mol. Nutr. Food Res. 60, 2467-2480. doi: 10.1002/mnfr.201500995

Fujiwara, Y., Komohara, Y., Ikeda, T., and Takeya, M. (2011). Corosolic acid inhibits glioblastoma cell proliferation by suppressing the activation of signal transducer and activator of transcription-3 and nuclear factor-kappa B in tumor cells and tumor-associated macrophages. Cancer Sci. 102, 206-211. doi: 10. $1111 / j .1349-7006.2010 .01772 . x$

Fujiwara, Y., Takaishi, K., Nakao, J., Ikeda, T., Katabuchi, H., Takeya, M., et al. (2013). Corosolic acid enhances the antitumor effects of chemotherapy on epithelial ovarian cancer by inhibiting signal transducer and activator of transcription 3 signaling. Oncol. Lett. 6, 1619-1623. doi: 10.3892/ol.2013. 1591

Fujiwara, Y., Takeya, M., and Komohara, Y. (2014). A novel strategy for inducing the antitumor effects of triterpenoid compounds: blocking the protumoral functions of tumor-associated macrophages via STAT3 inhibition. Biomed. Res. Int. 2014:348539. doi: 10.1155/2014/348539

\section{ACKNOWLEDGMENTS}

We thank Mr. Takenobu Nakagawa and Mrs. Ikuko Yoshida for their technical assistance.

\section{SUPPLEMENTARY MATERIAL}

The Supplementary Material for this article can be found online at: https://www.frontiersin.org/articles/10.3389/fphar. 2020.00262/full\#supplementary-material

Gao, L., Li, F., Dong, B., Zhang, J., Rao, Y., Cong, Y., et al. (2010). Inhibition of STAT3 and ErbB2 suppresses tumor growth, enhances radiosensitivity, and induces mitochondria-dependent apoptosis in glioma cells. Int. J. Radiat. Oncol. Biol. Phys. 77, 1223-1231. doi: 10.1016/j.ijrobp.2009.12.036

Hasegawa, H., and Uchiyama, M. (1998). Antimetastatic efficacy of orally administered ginsenoside $\mathrm{Rb} 1$ in dependence on intestinal bacterial hydrolyzing potential and significance of treatment with an active bacterial metabolite. Planta Medica 64, 696-700. doi: 10.1055/s-2006-957560

Horlad, H., Fujiwara, Y., Takemura, K., Ohnishi, K., Ikeda, T., Tsukamoto, H., et al. (2013). Corosolic acid impairs tumor development and lung metastasis by inhibiting the immunosuppressive activity of myeloid-derived suppressor cells. Mol. Nutr. Food Res. 57, 1046-1054. doi: 10.1002/mnfr.201200610

Hussain, S. F., Kong, L. Y., Jordan, J., Conrad, C., Madden, T., Fokt, I., et al. (2007). A novel small molecule inhibitor of signal transducers and activators of transcription 3 reverses immune tolerance in malignant glioma patients. Cancer Res. 67, 9630-9636. doi: 10.1158/0008-5472.CAN-07-1243

Iwamaru, A., Szymanski, S., Iwado, E., Aoki, H., Yokoyama, T., Fokt, I., et al. (2007). A novel inhibitor of the STAT3 pathway induces apoptosis in malignant glioma cells both in vitro and in vivo. Oncogene 26, 2435-2444. doi: 10.1038/sj. onc. 1210031

Jung, H. J., Kang, S. S., Hyun, S. K., and Choi, J. S. (2005). In vitro free radical and ONOO- scavengers from Sophora flavescens. Arch. Pharm. Res. 28, 534-540. doi: $10.1007 / \mathrm{BF} 02977754$

Kang, C. W., Kim, N. H., Jung, H. A., Choi, H. W., Kang, M. J., Choi, J. S., et al. (2016). Desmethylanhydroicaritin isolated from Sophora flavescens, shows antitumor activities in U87 MG cells via inhibiting the proliferation, migration and invasion. Environ. Toxicol. Pharmacol. 43, 140-148. doi: 10.1016/j.etap. 2016.03.003

Kida, H., Akao, T., Meselhy, M. R., and Hattori, M. (1997). Enzymes responsible for the metabolism of saikosaponins from Eubacterium sp. A-44, a human intestinal anaerobe. Biol. Pharm. Bull. 20, 1274-1278. doi: 10.1248/bpb.20.1274

Komohara, Y., Hirahara, J., Horikawa, T., Kawamura, K., Kiyota, E., Sakashita, N., et al. (2006). AM-3K, an anti-macrophage antibody, recognizes CD163, a molecule associated with an anti-inflammatory macrophage phenotype. J. Histochem. Cytochem. 54, 763-771. doi: 10.1369/jhc.5A6871.2006

Komohara, Y., Horlad, H., Ohnishi, K., Fujiwara, Y., Suzu, S., Eto, M., et al. (2011a). Macrophage infiltration and its prognostic relevance in clear cell renal cell carcinoma. Cancer Sci. 102, 1424-1431. doi: 10.1111/j.1349-7006.2011.01945.x

Komohara, Y., Jinushi, M., and Takeya, M. (2014). Clinical significance of macrophage heterogeneity in human malignant tumors. Cancer Sci. 105, 1-8. doi: $10.1111 /$ cas. 12314

Komohara, Y., Niino, D., Ohnishi, K., Ohshima, K., and Takeya, M. (2015). Role of tumor-associated macrophages in hematological malignancies: TAMs in hematological malignancies. Pathol. Int. 65, 170-176. doi: 10.1111/pin.12259

Komohara, Y., Ohnishi, K., Kuratsu, J., and Takeya, M. (2011b). Possible involvement of the M2 anti-inflammatory macrophage phenotype in growth of human gliomas. J. Pathol. 216, 15-24. doi: 10.1002/path.2370

Kristiansen, M., Graversen, J. H., Jacobsen, C., Sonne, O., Hoffman, H. J., Law, S. K., et al. (2001). Identification of the haemoglobin scavenger receptor. Nature 409, 198-201. doi: 10.1038/35051594

Kurahara, H., Shinchi, H., Mataki, Y., Maemura, K., Noma, H., Kubo, F., et al. (2011). Significance of M2-polarized tumor-associated macrophage 
in pancreatic cancer. J. Surg. Res. 167, e211-e219. doi: 10.1016/j.jss.2009. 05.026

Lai, X., Ye, H., Sun, C., Huang, X., Tang, X., Zeng, X., et al. (2013). Icaritin exhibits anti-inflammatory effects in the mouse peritoneal macrophages and peritonitis model. Int. Immunopharmacol. 16, 41-49. doi: 10.1016/j.intimp.2013.03.025

Lewis, C. E., and Pollard, J. W. (2006). Distinct role of macrophages in different tumor microenvironments. Cancer Res. 66, 605-612. doi: 10.1158/0008-5472. CAN-05-4005

Li, W. K., Zhang, R. Y., and Xiao, P. G. (1994). Epimedokoreanin B and Epimedokoreanin C from the aerial parts of Epimedium koreanum Nakai. Acta Pharm. Sin. 29, 835-839.

Mantovani, A., Biswas, S. K., Galdiero, M. R., Sica, A., and Locati, M. (2013). Macrophage plasticity and polarization in tissue repair and remodeling: macrophage plasticity and polarization in tissue repair and remodeling. J. Pathol. 229, 176-185. doi: 10.1016/j.it.2004.09.015

Mantovani, A., Sica, A., Sozzani, S., Allavena, P., Vecchi, A., and Locati, M. (2004). The chemokine system in diverse forms of macrophage activation and polarization. Trends Immunol. 25, 677-686. doi: 10.1016/j.it.2004. 09.015

Mantovani, A., Sozzani, S., Locati, M., Allavena, P., and Sica, A. (2002). Macrophage polarization: tumor-associated macrophages as a paradigm for polarized M2 mononuclear phagocytes. Trends Immunol. 7, 549-555. doi: 10.1016/s1471-4906(02)02302-5

Martinez, F. O., Gordon, S., Locati, M., and Mantovani, A. (2006). Transcriptional profiling of the human monocyte-to-macrophage differentiation and polarization: new molecules and patterns of gene expression. J. Immunol. 177, 7303-7311. doi: 10.4049/jimmunol.177.10.7303

Mills, C. D., Kincaid, K., Alt, J. M., Heilman, M. J., and Hill, A. M. (2000). M1/M-2 macrophages and the Th1/Th2 paradigm. J. immunol. 164, 6166-6173. doi: 10.4049/jimmunol.164.12.6166

Mizuno, M., Iinuma, M., and Tanaka, T. (1988). Flavonol glyeosides in the roots of Epimedium diphyllum. Phytochemistry 27, 36-45.

Philippidis, P., Mason, J. C., Evans, B. J., Nadra, I., Taylor, K. M., Haskard, D. O., et al. (2003). Hemoglobin scavenger receptor CD163 mediates interleukin10 release and heme oxygenase-1 synthesis: antiinflammatory monocytemacrophage responses in vitro, in resolving skin blisters in vivo, and after cardiopulmonary bypass surgery. Circ. Res. 94, 119-126. doi: 10.1161/01.RES. 0000109414.78907.F9

Pollard, J. W. (2004). Tumour-educated macrophages promote tumour progression and metastasis. Nat. Rev. Cancer 4, 71-78. doi: 10.1038/nrc1256

Porcheray, F., Viaud, S., Rimaniol, A. C., Leone, C., Samah, B., Dereuddre-Bosquet, N., et al. (2005). Macrophage activation switching: an asset for the resolution of inflammation. Clin. Exp. Immunol. 142, 481-489. doi: 10.1111/j.1365-2249. 2005.02934.x

Quan, X., Dujuan, X., Zhaogang, H., Jianjun, L., Xinqun, W., Xiu, W., et al. (2010). Preparation of icariside II from icariin by enzymatic hydrolysis method. Fitoterapia 81, 437-442. doi: 10.1016/j.fitote.2009.12.006

Shiraishi, D., Fujiwara, Y., Horlad, H., Saito, Y., Iriki, T., Tsuboki, J., et al. (2018). CD163 is required for protumoral activation of macrophages in human and murine sarcoma. Cancer Res. 78, 3255-3266. doi: 10.1158/0008-5472.CAN-172011

Sica, A., and Bronte, V. (2007). Altered macrophage differentiation and immune dysfunction in tumor development. J. Clin. Invest. 117, 1155-1166. doi: 10.1172/ JCI31422

Stein, M., Keshay, S., Harris, N., and Gordon, S. (1992). Interleukin 4 potently enhances murine macrophage mannose receptor activity: a marker of alternative immunologic macrophage activation. J. Exp. Med. 178, 287-292. doi: $10.1084 /$ jem.176.1.287

Takeya, M., and Komohara, Y. (2016). Role of tumor-associated macrophages in human malignancies: friend or foe: TAMs in human malignancies. Pathol. Int. 66, 491-505. doi: 10.1111/pin. 12440

Thoennissen, N. H., Iwanski, G. B., Doan, N. B., and Okamoto, R. (2009). Cucurbitacin B induces apoptosis by inhibition of the JAK/STAT pathway and potentiates antiproliferative effects of gemcitabine on pancreatic cancer cells. Cancer Res. 69, 5876-5884. doi: 10.1158/0008-5472.CAN-09-0536

Tsuboki, J., Fujiwara, Y., Horlad, H., Shiraishi, D., Nohara, T., Tayama, S., et al. (2016). Onionin A inhibits ovarian cancer progression by suppressing cancer cell proliferation, and the protumour function of macrophages. Sci. Rep. 6:29588. doi: 10.1038/srep29588

Tu, B., Du, L., Fan, Q. M., and Tang, Z. (2012). STAT3 activation by IL-6 from mesenchymal stem cells promotes the proliferation and metastasis of osteosarcoma. Cancer Lett. 325, 80-88. doi: 10.1016/j.canlet.2012.06.006

Wen-Kui, L., Pei-Gen, X., and Jing-Qi, P. (1998). Complete assainment of $1 \mathrm{H}$ and 13C NMR spectra of icarisoside A and epimedoside C. Magn. Reson. Chem. 36, 303-304. doi: 10.1002/mrc.2681

Yokogami, K., Wakisaka, S., Avruch, J., and Reeves, S. A. (2000). Serine phosphorylation and maximal activation of STAT3 during CNTF signaling is mediated by the rapamycin target mTOR. Curr. Biol. 10, 47-50. doi: 10.1016/ s0960-9822(99)00268-7

Yu, H., Kortylewski, M., and Pardoll, D. (2007). Crosstalk between cancer and immune cells: role of STAT3 in the tumour microenvironment. Nat. Rev. Immunol. 7, 41-51. doi: 10.1038/nri1995

Zhou, J., Wu, J., Chen, X., and Fortenbery, N. (2011). Icariin and its derivative, ICT, exert anti-inflammatory, antitumor effects, and modulate myeloid derived suppressive cells (MDSCs) functions. Int. Immunopharmacol. 11, 890-898. doi: 10.1016/j.intimp.2011.01.007

Conflict of Interest: The authors declare that the research was conducted in the absence of any commercial or financial relationships that could be construed as a potential conflict of interest.

Copyright (C) 2020 Pan, Fujiwara, Horlad, Shiraishi, Iriki, Tsuboki, Ikeda and Komohara. This is an open-access article distributed under the terms of the Creative Commons Attribution License (CC BY). The use, distribution or reproduction in other forums is permitted, provided the original author(s) and the copyright owner(s) are credited and that the original publication in this journal is cited, in accordance with accepted academic practice. No use, distribution or reproduction is permitted which does not comply with these terms. 